\title{
Awareness and Knowledge of Autism Spectrum Disorders Among Community Pharmacists in Khartoum state(Sudan), 2018
}

\author{
Nadine Hassan Ali ${ }^{* *}$ and Ahmed H. Arbab ${ }^{2 *}$ \\ 1 Nadine Hassan Ali: M.Pharm (Clinical pharmacy), B.Pharm (Hons), Nile University, Khartoum, Sudan \\ 2 Ahmed H. Arbab: Ph.D., M. Pharm, B.Pharm(Hons), University of Khartoum, Khartoum, P.O.Box 1996. Sudan
}

\begin{abstract}
This study was conducted to assess awareness and knowledge of autism spectrum disorders (ASDs) among community pharmacists in Khartoum state. A cross-sectional study was conducted among 345 community pharmacists. All the data were collected from randomly selected by questionnaire. The results indicated gaps in participant awareness and knowledge regarding ASDs. The participant reported low familiarity with ASDs. The median score on 12 item knowledge section regarding ASDs was about 60\%. Having continuing education(CE) or training program on ASDs was significantly associated with familiarity and confidence scores. About $64 \%$ of the participants reported as not feeling confident enough in their ability to counsel parents about medications used for their children with ASDs and their side effects. Pharmacists' awareness and knowledge regarding ASDs needs to be improved. Providing continuing education programs should be considered to increase pharmacist's awareness and knowledge regarding ASDs.
\end{abstract}

Keywords: Autism spectrum disorders, Community pharmacist, Behavioral disorders.

\section{INTRODUCTION}

Autism Spectrum Disorders (ASDs) are complex, lifelong neurodevelopmental and behavioral disorders manifests as difficulty communicating, abnormal social interaction, and delays in developmental skills ${ }^{(1)}$. The first reported on ASDs was Kanner in 1943 and since then the global prevalence has been increasing consistently ${ }^{(2)}$, The Centers for Disease Control (CDC) estimated the prevalence of ASDs nationally as 1 in every 59 children $^{(3)}$, it's 3-4 more prevalent

ORCIDS

E.mail: Nada00757@gmail.com ORCID:0000000189541134

Email: arbabssn@gmail.com, ORCID:0000-0002-5975-112X

(Received 01 May 2020, accepted 10 September 2020) 
among males than females ${ }^{(4)}$, and more prevalent than juvenile diabetes, pediatric cancer, and pediatric AIDS combined ${ }^{(3)}$. Because of increasing prevalence, ASDs is widely considered to be an emerging public health concern ${ }^{(5)}$, ASDs were not shown to be associated with a certain racial, ethnic and socioeconomic group $^{(2)}$, it occurs because of an interaction of genetic and environmental factors $^{(6)}$. Currently, there is no cure for autism ${ }^{(7)}$ but there are pharmacological and non-pharmacological treatment options to alleviate the symptoms associated with ASDs. ${ }^{(8)}$.

Pharmacological treatment has become increasingly popular in managing behavioral symptoms of ASDs like aggressiveness, anxiety, hyperactivity, and tantrums ${ }^{(8-10)}$, Risperidone and aripiprazole are drugs approved by The Food and Drug Administration (FDA) for the management of behavioral symptoms associated with ASDs. ${ }^{(11,12)}$ Other pharmacological classes used to manage symptoms of ASDs include Central Nervous System (CNS) stimulants, antidepressants, and anxiolytics ${ }^{(12)}$. In today's healthcare system, the role of pharmacists goes beyond merely dispensing medications, they are considered as trusted and easily accessible health care providers ${ }^{(13)}$. Therefore, the community pharmacist could play an important role in the care of people with ASDs and help them achieve the best results from their medications. The pharmacological treatment of children with ASDs can be challenging. A previous study showed that children with ASDs are particularly susceptible to adverse effects and may exhibit paradoxical reactions to medications. ${ }^{(14,15)}$. Therefore, improperly trained pharmacists or those with less familiarity and knowledge would fail to do so. This might have consequences on their role in providing healthcare and might result in deteriorating the health and quality of life of their patients.

As the community pharmacist is the first line of interaction with families and/ or caregivers in our community, they should be more familiar and knowledgeable about ASDs resources allocated for ASDs in their communities and should guide families of children with ASDs to relevant professional resources. Unfortunately, previous studies reported cases of pharmacists lacking knowledge and awareness of the ASDs area. ${ }^{(16-18)}$ Community pharmacists practicing in Khartoum(Sudan) were not previously assessed for their awareness and knowledge of ASDs. Therefore, this study aims to assess awareness and knowledge of autism spectrum disorders (ASDs) among community pharmacists.

\section{METHODOLOGY}

Study setting and population: This study was conducted in Khartoum state, the national capital of Sudan from April to August 2018. The study population was registered community pharmacists practicing in the Khartoum state. 
According to the Sudanese General Directorate of Pharmacy, the number of registered community pharmacists when this study started is $2265{ }^{(19)}$

Study design and sampling: A descriptive cross-sectional survey design was used for this study. The sample size needed for this study was calculated according to this equation:

$\left(n p=\frac{N}{1+N(e) 2}\right)$.

Where $\mathrm{N}=$ target population, $\mathrm{n}=$ sample size, $\mathrm{e}=$ margin of error (0.05). The sample size was estimated at 95\% confidence interval with a default margin of error of $5 \%$. The sample size was 345 pharmacists.

Sampling conducted by selecting individual units (Khartoum state pharmacies) by stratified sampling to ensure representativeness of the study. Khartoum state pharmacies were broken down into seven strata by the area (locality). Samples were randomly selected from each stratum according to their percent in the population as follow; Khartoum (23\%), Khartoum North (14\%), Omdurman (13\%), Sharq an-Nil(13\%), Jabal Awliya(14\%), Om Badda, (11\%), and Karari (12\%). One of the pharmacists who are working in the selected pharmacy was randomly selected and included in the study.

Data collection: Face to face paper-based questionnaires were administered after obtaining participants' informed consent by the researcher itself and trained data collectors who visited the community pharmacists in their workplaces and explained the purpose of the study. The questionnaire sections were adopted from similar previous studies ${ }^{(16,19-22)}$. The questionnaire contained four sections, the first section collected demographic and practice details of the study participants, also pharmacist was asked if they had a course(s) or lecture(s) on ASDs during their pharmacy degree program and if they had continuing education (CE) or training program on ASDs. The second section contained six items to measure pharmacists' degree of familiarity with symptoms, treatment, and community resources of ASDs. The participant pharmacist had to indicate the degree of familiarity on each item on a Likert scale of five options. The third section contained 12 items to measure pharmacists' knowledge of the etiology, prevalence, and treatment of ASDs. The fourth section contained four items to measure pharmacists' training and confidence in medication management of ASDs. Pharmacists had to indicate the degree of their agreement with the 4 items on a Likert scale of five options. The questionnaire was tested in twenty community pharmacies as a pilot study, and these pharmacies were excluded when the study was conducted. 
Statistical analysis: Statistical Package for Social Sciences software, version 21.o (IBM SPSSInc., Chicago, IL) was used for the analysis of data. Initially, all information gathered via directly administered questionnaire are coded into variables. The normality of data was tested using the Kolmogorov-Smirnov test. Data that were not normally distributed expressed as medians then categorized into poor (less than the median) and good (median and above) and compared using Mann-Whitney U-Test. The reliability test of the questionnaire was tested using Cronbach's Alpha= 0.618 (62\%), Spearman's rho correlation was used to investigate the correlation between familiarity, knowledge, and confidence scores. and binary logistic regression was used to present results. A $p$-value of less than 0.05 was considered statistically significant.

Ethical approval: This study received ethical approval from the ethical committee of the faculty of pharmacy, University of Khartoum. Pharmacists who participated in this study also gave informed consent before they took part.

\section{RESULTS and DISCUSSION}

\section{Demographic and practice characteristics of the study participants}

A total of 345 community pharmacist participants in the study giving a response rate of $100 \%$. The study participants practicing in the 7 localities of Khartoum state was found between 1996- 2016. The demographic and practice-related characteristics of the participant pharmacists are listed in Table 1. 
Table 1. Demographic and practice characteristics of the participant community pharmacists surveyed $(n=345)$

\begin{tabular}{|c|c|c|}
\hline Demographic variables & Number & Percentage \\
\hline \multicolumn{3}{|l|}{ Age (Years) } \\
\hline$(\leq 35)$ & 328 & $95.1 \%$ \\
\hline (>35) & 17 & $4.9 \%$ \\
\hline \multicolumn{3}{|l|}{ Gender } \\
\hline Male & 93 & $27 \%$ \\
\hline Female & 252 & $73 \%$ \\
\hline \multicolumn{3}{|l|}{ Number of years in practice } \\
\hline$(<5)$ & 248 & $71.9 \%$ \\
\hline$(\geq 5)$ & 97 & $28.1 \%$ \\
\hline \multicolumn{3}{|l|}{ Job Title } \\
\hline Staff pharmacist & 271 & $78.6 \%$ \\
\hline Others(manager,owner) & 74 & $21.4 \%$ \\
\hline \multicolumn{3}{|l|}{ Highest degree } \\
\hline Higher degree (MSc and Ph.D.) ${ }^{*}$ & 70 & $20.3 \%$ \\
\hline Basic degree (BSc) & 275 & $79.7 \%$ \\
\hline \multicolumn{3}{|c|}{$\begin{array}{l}\text { Had attend ASDs course(s) or lecture(s) during pharmacy } \\
\text { degree }\end{array}$} \\
\hline Yes & 34 & $9.9 \%$ \\
\hline No & 311 & $90.1 \%$ \\
\hline \multicolumn{3}{|l|}{ Had attended ASDs CE program* } \\
\hline Yes & 23 & $6.7 \%$ \\
\hline No & 322 & $93.3 \%$ \\
\hline
\end{tabular}

*ASDs autism spectrum disorders, BSc bachelor degree in pharmacy, MSc master of science degree, Ph.D. doctor of philosophy degree, CE continuing education The demographic and practice-related characteristics of the pharmacists from different localities were similar. About $73 \%$ of community pharmacists were female and Nearly $78 \%$ of community pharmacists identified themselves as staff pharmacists. About $77 \%$ of the community pharmacists had basic pharmacy degrees and about $80 \%$ had less than 5 years practicing pharmacy in Khartoum. Only about $10 \%$ had either course(s) or lecturer(s) on ASDs during their pharmacy school program, and about 6\% had Continuing Education Programme (CEP) on ASDs as shown in Table 1. 


\section{The familiarity of pharmacists with Symptoms, Treatment, and Community Resources of ASDs}

Table (2) describes the participant pharmacists' degree of familiarity with ASDs. Majority of the participants showed a low degree of familiarity (67.9\%) with symptoms, treatment, and community resources of ASDs, the median score on the Likert scale was 13 . Furthermore, about $74 \%$ of participants showed low familiarity with classes of medications used to manage symptoms of ASDs, and nearly $59 \%$ low familiar with their side effects. About $74 \%$ were not sufficiently familiar with the specific behavior that medication seeks to alleviate.

Table 2. Degree of familiarity with ASDs symptoms, treatment, and community resources of the participant community pharmacists surveyed $(n=345)$

\begin{tabular}{|c|c|c|c|c|c|}
\hline Familiarity variables ( $n=345$ ) & $\begin{array}{l}\text { Not at all } \\
\text { familiar } \\
\mathrm{N}(\%)\end{array}$ & $\begin{array}{l}\text { Not familiar } \\
\qquad \mathrm{N}(\%)\end{array}$ & $\begin{array}{c}\text { Somewhat } \\
\text { familiar } \\
N(\%)\end{array}$ & $\begin{array}{l}\text { Familiar } \\
\mathrm{N}(\%)\end{array}$ & $\begin{array}{c}\text { Extremely } \\
\text { familiar } \\
\mathrm{N}(\%)\end{array}$ \\
\hline \multirow{2}{*}{$\begin{array}{l}\text { Are you familiar with the different } \\
\text { symptoms of ASDs*? }\end{array}$} & 24 & 94 & 165 & 54 & 8 \\
\hline & $7 \%$ & $27.2 \%$ & $47.8 \%$ & $15.7 \%$ & $2.3 \%$ \\
\hline \multirow{2}{*}{$\begin{array}{l}\text { Are you familiar with different classes } \\
\quad \text { of medications? } \\
\text { (e.g.antipsychotics, antidepressants, } \\
\text { stimulants ) that are used in treating } \\
\text { the symptoms of ASDs? }\end{array}$} & 127 & 128 & 76 & 12 & 2 \\
\hline & $36.8 \%$ & $37.1 \%$ & $22 \%$ & $3.5 \%$ & $0.6 \%$ \\
\hline \multirow{2}{*}{$\begin{array}{c}\text { Are you familiar with specific } \\
\text { behaviors associated with ASDs that } \\
\text { medications seek to alleviate? (e.g. } \\
\text { hyperactivity, OCD, and self-injury) }\end{array}$} & 124 & 131 & 72 & 16 & 2 \\
\hline & $35.9 \%$ & $38 \%$ & $20.9 \%$ & $4.6 \%$ & $0.6 \%$ \\
\hline \multirow{2}{*}{$\begin{array}{l}\text { Are you familiar with various side } \\
\text { effects produced by medications used } \\
\text { in the treatment of ASDs symptoms } \\
\text { (e.g. sedation, irritation, and } \\
\text { extrapyramidal symptoms)? }\end{array}$} & 78 & 125 & 118 & 21 & 3 \\
\hline & $22.6 \%$ & $36.2 \%$ & $34.2 \%$ & $6.1 \%$ & $0.9 \%$ \\
\hline \multirow{2}{*}{$\begin{array}{l}\text { Are you familiar with how to help } \\
\text { families sort through informed } \\
\text { decisions about their children with } \\
\text { ASDs? }\end{array}$} & 61 & 172 & 76 & 34 & 2 \\
\hline & $17.7 \%$ & $49.9 \%$ & $22 \%$ & $9.9 \%$ & $0.6 \%$ \\
\hline \multirow{2}{*}{$\begin{array}{l}\text { Are you familiar with community } \\
\text { resources in your region that can be } \\
\text { used for the referral of a child who } \\
\text { is exhibiting symptoms commonly } \\
\text { associated with ASDs? }\end{array}$} & 73 & 161 & 77 & 33 & 1 \\
\hline & $21.2 \%$ & $46.7 \%$ & $22.3 \%$ & $9.6 \%$ & $0.3 \%$ \\
\hline
\end{tabular}

*ASDs autism spectrum disorders, OCD obsessive-compulsive disorder

\section{Knowledge of Pharmacists of Etiology, Prevalence, and Treatment of ASDs}

Table (3) describes a participant's knowledge of ASDs based on their response to a series of true/false statements. The median score was nearly $58 \%$. About 95\% of participants knew that the children with ASDs have impairment in so- 
cial interaction, communication or language, and behavioral development (variable 1), and about $87 \%$ knew that ASDs are developmental disorders(variable 2). Only about $30 \%$ of participants knew that ASDs are more prevalent than down syndrome and juvenile diabetes (variables 5 and 4). About $51 \%$ knew that ASDs are not curable (variable 6), and 55\% knew that risperidone and aripiprazole have been approved by the FDA for the treatment of irritability associated with ASDs (variable 7). Only $14 \%$ and $25 \%$ don't know that vaccine cannot cause ASDs and ASDs not exists only in childhood (variable 8,9 respectively). Nearly half of the participants knew ASDs are rare disorders (variable 12), and about $81 \%$ knew that genetic factors play a major role in the etiology of ASDs(variable 11). Only about 29\% knew that ASDs are not caused because of emotionally distant, rejecting parents(variable 10) and about $43 \%$ knew ASDs occur more commonly among males than females(variable 3 ).

Table 3. Knowledge of etiology, prevalence, and treatment of ASDs of the participant community pharmacists surveyed $(n=345)$.

\begin{tabular}{|c|c|c|}
\hline Knowledge variables $(n=345)$ & $\begin{array}{c}\text { True } \\
\text { N (\%) }\end{array}$ & $\begin{array}{l}\text { False } \\
\text { N (\%) }\end{array}$ \\
\hline \multirow{2}{*}{ 1- ASDs are developmental disorders } & 302 & 43 \\
\hline & $87.5 \%$ & $12.5 \%$ \\
\hline \multirow{2}{*}{$\begin{array}{l}\text { 2- Children with ASDs have impairments in social interaction, communication or } \\
\text { language, and behavioral development }\end{array}$} & 330 & 15 \\
\hline & $95.7 \%$ & $4.3 \%$ \\
\hline \multirow{2}{*}{ 3- ASDs occur more commonly among males than females } & 151 & 194 \\
\hline & $43.8 \%$ & $56.2 \%$ \\
\hline \multirow{2}{*}{ 4- ASDs is more prevalent than juvenile diabetes } & 97 & 248 \\
\hline & $28.1 \%$ & $71.9 \%$ \\
\hline \multirow{2}{*}{ 5- ASDs is more prevalent than down syndrome } & 115 & 230 \\
\hline & $33.3 \%$ & $66.7 \%$ \\
\hline \multirow{2}{*}{ 6- ASDs is curable } & 168 & 177 \\
\hline & $48.7 \%$ & $51.3 \%$ \\
\hline \multirow{2}{*}{$\begin{array}{l}\text { 7- Risperidone and aripiprazole have been approved by the FDA for the treatment } \\
\text { of irritability associated with ASDs }\end{array}$} & 191 & 154 \\
\hline & $55.4 \%$ & $44.6 \%$ \\
\hline \multirow{2}{*}{ 8- Vaccines can cause ASDs } & 50 & 295 \\
\hline & $14.5 \%$ & $85.5 \%$ \\
\hline \multirow{2}{*}{ 9- ASDs exists only in childhood } & 89 & 256 \\
\hline & $25.8 \%$ & $74.2 \%$ \\
\hline \multirow{2}{*}{ 10- ASDs are caused because of emotionally distant, rejecting parents } & 243 & 102 \\
\hline & $70.4 \%$ & $29.6 \%$ \\
\hline \multirow{2}{*}{ 11- Genetic factors play a major role in the etiology of ASDs } & 281 & 64 \\
\hline & $81.4 \%$ & $18.6 \%$ \\
\hline \multirow{2}{*}{ 12- ASDs are rare disorders } & 171 & 174 \\
\hline & $49.6 \%$ & $50.4 \%$ \\
\hline
\end{tabular}

ASDs autism spectrum disorders, FDA food, and drug administration Correct answers are in boldface 


\section{Training and Confidence of Pharmacists in Medication Management of ASDs}

Table (4) described the training and confidence of pharmacists in medication management of ASDs. About $64 \%$ of the participants reported as not feeling confident enough in their ability to counsel parents about medications used for their children with ASDs and their side effects, and about 54\% reported not feeling comfortable enough dispensing medications for individuals with ASDs. But $89 \%$ agreed that they would benefit from taking $\mathrm{CE}$ or training programs in the ASDs area, and nearly $91 \%$ agreed that pharmacy curricula should include courses or lectures on ASDs.

Table 4. Training and confidence of the participant community pharmacists surveyed in medication management of ASDs $(n=345)$.

\begin{tabular}{|c|c|c|c|c|c|}
\hline Confidence Variables (n=345) & $\begin{array}{c}\text { Strongly } \\
\text { disagree } \\
\mathbf{N}(\%)\end{array}$ & $\begin{array}{c}\text { Disagree } \\
\mathbf{N}(\%)\end{array}$ & $\begin{array}{c}\text { Neutral } \\
\mathbf{N}(\%)\end{array}$ & $\begin{array}{c}\text { Agree } \\
\mathbf{N}(\%)\end{array}$ & $\begin{array}{c}\text { Strongly } \\
\text { agree } \\
\mathbf{N}(\%)\end{array}$ \\
\hline $\begin{array}{c}\text { I feel confident in my ability } \\
\text { to counsel parents about the } \\
\text { medication profile and side effects } \\
\text { of prescriptions being used for the } \\
\text { treatment of their child with ASDs }\end{array}$ & $13.6 \%$ & $51 \%$ & $17.7 \%$ & $12.5 \%$ & $3.2 \%$ \\
\hline $\begin{array}{c}\text { I feel comfortable dispensing } \\
\text { medications used in the treatment } \\
\text { of ASDs }\end{array}$ & 32 & 152 & 74 & 75 & 12 \\
\cline { 2 - 6 } & $9.3 \%$ & $44.1 \%$ & $21.4 \%$ & $21.7 \%$ & $3.5 \%$ \\
\hline $\begin{array}{c}\text { I feel that I could benefit from taking } \\
\text { a continuing education or training } \\
\text { program in the area of ASDs }\end{array}$ & 14 & 10 & 13 & 179 & 129 \\
\cline { 2 - 6 } & $4.1 \%$ & $2.9 \%$ & $3.8 \%$ & $51.9 \%$ & $37.4 \%$ \\
\hline $\begin{array}{c}\text { I feel that the pharmacy school } \\
\text { curriculum should include a course or } \\
\text { lecture in the area of ASDs }\end{array}$ & 11 & 6 & 12 & 179 & 137 \\
\cline { 2 - 6 } & $3.2 \%$ & $1.7 \%$ & $3.5 \%$ & $51.9 \%$ & $39.7 \%$ \\
\hline
\end{tabular}

ASDs autism spectrum disorders

\section{Association of characteristics of the participants and familiarity and knowledge}

Comparing the characteristic of the participant using the Mann-Whitney $U$ test, a certain variable like having a CE program on ASDs was significantly associated ( $\mathrm{p}$ value $<0.05$ ) with familiarity score and confidence score, as shown in Table 5. On the other hand, age, gender, practice setting, number of years in practice, job title, and a degree in pharmacy were not significantly associated with familiarity score. 
Table 5. Association of characteristics of the study pharmacists with familiarity, knowledge and confidence scores

\begin{tabular}{|c|c|c|c|c|c|c|c|}
\hline \multicolumn{8}{|c|}{ Mann-Whitney U-Test } \\
\hline \multirow{2}{*}{\multicolumn{2}{|c|}{$\begin{array}{l}\text { Variables } \\
\text { Mean Rank }\end{array}$}} & \multicolumn{2}{|c|}{ Familiarity } & \multicolumn{2}{|c|}{ Knowledge } & \multicolumn{2}{|c|}{ Confidence } \\
\hline & & P-Value & $\begin{array}{l}\text { Mean } \\
\text { Rank }\end{array}$ & P-Value & $\begin{array}{l}\text { Mean } \\
\text { Rank }\end{array}$ & P-Value & \\
\hline \multirow{2}{*}{ Age (Years) } & $(\leq 35)$ & 170.62 & \multirow{2}{*}{$0.051^{*}$} & 174.24 & \multirow{2}{*}{$0.301^{*}$} & 173.17 & \multirow{2}{*}{$0.889^{*}$} \\
\hline & $(>35)$ & 218.85 & & 149.03 & & 169.76 & \\
\hline \multirow{2}{*}{ Gender } & Male & 180.47 & \multirow{2}{*}{$0.396^{\star}$} & 184.01 & \multirow{2}{*}{$0.205^{\star}$} & 184.11 & \multirow{2}{*}{$0.201^{*}$} \\
\hline & Female & 170.24 & & 168.94 & & 168.9 & \\
\hline \multirow{2}{*}{$\begin{array}{l}\text { Number of years } \\
\text { in practice }\end{array}$} & $(<5)$ & 170.96 & \multirow{2}{*}{$0.541^{*}$} & 169.9 & \multirow{2}{*}{$0.347^{\star}$} & 170.04 & \multirow{2}{*}{$0.370^{*}$} \\
\hline & $(\geq 5)$ & 178.23 & & 180.94 & & 180.57 & \\
\hline \multirow[t]{2}{*}{ Job Title } & $\begin{array}{c}\text { Staff } \\
\text { pharmacist }\end{array}$ & & \multirow[t]{2}{*}{$0.038^{\star \star}$} & 168.88 & \multirow[t]{2}{*}{$0.135^{\star}$} & 174.45 & \multirow[t]{2}{*}{$0.599^{\star}$} \\
\hline & Others & 194.25 & & 188.1 & & 167.68 & \\
\hline \multirow{2}{*}{ Highest degree } & $\mathrm{MSc}$ and $\mathrm{PhD}$ & 190.61 & \multirow{2}{*}{$0.096^{\star}$} & 188.39 & \multirow{2}{*}{$0.141^{*}$} & 161.33 & \multirow{2}{*}{$0.265^{\star}$} \\
\hline & BSc & 168.52 & & 169.08 & & 175.97 & \\
\hline \multirow{2}{*}{$\begin{array}{c}\text { Had attend } \\
\text { ASDs course(s) } \\
\text { or lecture(s) } \\
\text { during pharmacy } \\
\text { degree }\end{array}$} & Yes & 201.25 & \multirow{2}{*}{$0.081^{*}$} & 187.85 & \multirow[t]{2}{*}{$0.352^{*}$} & & \multirow[t]{2}{*}{$0.371^{*}$} \\
\hline & No & 169.91 & & 171.38 & & 171.44 & \\
\hline \multirow{2}{*}{$\begin{array}{l}\text { Had attended } \\
\text { ASDs CEP }\end{array}$} & Yes & 215.52 & \multirow{2}{*}{$0.033^{\star *}$} & 194.63 & \multirow{2}{*}{$0.273^{*}$} & 213.22 & \multirow{2}{*}{$0.042^{* *}$} \\
\hline & No & 169.96 & & 171.45 & & 170.13 & \\
\hline
\end{tabular}

**P-value $\leq 0.05$ that's considered as statistically significant.

*P-value $>0.05$ that's considered as statistically insignificant.

Confidence scores significantly correlated with familiarity scores (spearman's rho $=0.312, p$-value $<0.01$ ) and knowledge scores (spearman's rho=0.169 $p$ value <0.01), also there were significant correlation between familiarity and knowledge scores (spearman's rho=0.227 $p$-value<0.01). Binary logistic regression analysis was conducted to know factors that could be associated with the low familiarity, knowledge, and confidence scores. The analysis revealed that older age is significantly associated with poor knowledge ( $p$-value o.o37). Moreover, participant's poor knowledge and poor familiarity was significantly contributed to poor confidence with $p$-value 0.001 and 0.047 respectively.

To the best knowledge of the investigators, this is the first study to assess community pharmacist's awareness and knowledge regarding Autism Spectrum Disorders(ASDs) in Sudan. The present study used variables from previous studies that were used to measure similar constructs among healthcare provid- 
ers. ${ }^{(16,18,20-22)}$. As shown in Table 3, about 87\% of participants knew that ASDs are developmental disorders. This finding was higher than the result observed in studies from Palestine ${ }^{(18)}$ and Mississippi ${ }^{(20)}$, in which the percentage was $40 \%$ and $76 \%$ respectively.

In agreement with the studies from Mississippi surveyed pharmacists and pharmacy students ${ }^{(16,20)}$, in the current study, about $96 \%$ of the participants knew that children with ASDs have impairments in social interaction, communication or language, and behavioral development. However, only about $44 \%$ of the participant knew that ASDs are more common in males than in females. This finding is close to the study conducted in Palestine ${ }^{(18)}$, but lower than the findings obtained from the pharmacists and pharmacy students from Mississippi were about ( $85 \%)$ of participants correctly answered this statement ${ }^{(16,20)}$. On the other hand, only about 30\% of the participants knew about the prevalence of ASDs compared to juvenile diabetes and Down syndrome, respectively. This finding is consistent with a study carried out in Palestine, However, it is contrary to the study from Mississippi ${ }^{(20)}$.

Although the primary duty of the community pharmacist is not diagnosis, participant pharmacists were somewhat familiar with the different symptoms of ASDs. About $34 \%$ of the participant were minimally familiar with signs and symptoms of ASDs, our results were consistent with those reported among nurses in the state of Virginia and pharmacists in Palestine ${ }^{(22,18)}$. However, pharmacists and pharmacy students in Mississippi were relatively more familiar with the signs and symptoms of ASDs as only $25 \%$ of them reported as either not familiar at all or not familiar with the different symptoms of ASDs. ${ }^{(16,20)}$.

Pharmacists assuming educative roles might need to educate families of people with ASDs on these symptoms. Pharmacists who are not familiar with symptoms of ASDs cannot assume this role. This can be even worse when pharmacists are not familiar with how to help families sort through information to make informed decisions about their child with ASDs. This study revealed that about $67 \%$ of the pharmacists reported themselves as either not familiar at all or not familiar with how to help families sort through information to make informed decisions about their child with ASDs (Table 2). This percentage was comparable to those reported by Palestinian pharmacists and Mississippi pharmacists and pharmacy students. $(16,18,20)$. Moreover, about $68 \%$ of the pharmacists in this study were not familiar with community resources in their region that can be used for the referral of a child who was exhibiting symptoms commonly associated with ASDs. These results were comparable to those reported by Mississippi pharmacists and pharmacy students ${ }^{(16,20)}$ and similar to the studies done on Palestinian pharmacists ${ }^{(18)}$. 
Although, some studies concluded that early diagnosis improves the prognosis of ASDs in children ${ }^{(23)}$. Unfortunately, in many cases there were significant delays in diagnosing children with $\mathrm{ASDs}^{(24)}$. In modern healthcare delivery systems, the role of pharmacists in caring for patients with chronic diseases is expanding. Subsequently, patients often report a good relationship with their pharmacists ${ }^{(13)}$ previous research showed that both patients and primary healthcare physicians wanted pharmacists to play a larger role in providing information to patients. ${ }^{(13)(25)}$. When asked to indicate the degree of familiarity of participants with the different classes of medications (e.g. antipsychotics, antidepressants, stimulants) that are used in treating the symptoms of ASDs, nearly $74 \%$ of the participants in this study reported themselves as either not familiar at all or not familiar. This value was quite higher than that reported in study conducted in Palestine, where 62\% of the pharmacists reported as not feeling confident enough in their ability to counsel parents about ASDs medications ${ }^{18}$. This finding highlight the need to increase knowledge of pharmacists on the classes of medications used to treat symptoms of ASDs.

Furthermore, about $58 \%$ of the pharmacists were either not familiar at all or not familiar with various side effects produced by medications used in the treatment of symptoms of ASD. These results are worrisome, as pharmacists are expected to be familiar with medications used in the management of different diseases and the side effects associated with the use of these medications. Therefore, it was not surprising that nearly $64 \%$ of the pharmacists in this study were not confident in their ability to counsel parents about the medications being used for the treatment of their child with ASDs.Previous studies reported that children with ASDs are prescribed psychotropic medications ${ }^{(1,12)}$ These medications are associated with weight gain, sedation, and/or tardive dyskinesia which might further complicate the management of ASDs in children ${ }^{(26) .}$

Approximately $49 \%$ of the participant in this study thought ASDs were rare disorders, $70 \%$ thought ASDs are caused because of emotionally distant, rejecting parents, $25 \%$ thought that ASDs exist only in childhood, and about $18 \%$ did not know that genetics play a major role in the etiology of ASDs. About $14 \%$ believed that the vaccine causes ASDs. Pharmacists and other healthcare professionals are in a position to influence parent's decisions on vaccinations ${ }^{(27)}$. Previous studies showed that believing in this myth had negatively affected vaccination rates in the US and UK. ${ }^{(28,29) .}$

Having CEP in the area of ASDs was significantly associated with familiarity and confidence scores. In this study, confidence scores correlated with both familiarity and knowledge scores. Despite the obvious low Spearman's rho, there 
was a significant positive correlation between the scores. This indicates that the pharmacists who were relatively familiar and knowledgeable of ASDs were more confident in their ability to counsel parents about the medication profile and side effects of prescriptions being used for the treatment of their child with ASDs as well as dispensing medications used to treat symptoms of ASDs. A previous study showed that on many occasions, education increases familiarity and knowledge in certain domains ${ }^{(30)}$. In this study, about $89 \%$ of the participants agreed that they could benefit from taking a CE or training program in the area of ASDs. Similarly, about 95\% agreed that the pharmacy curriculum should include a course or lecture in the area of ASDs.

These results highlight the need to integrate educational interventions on ASDs in pharmacy curricula. Policymakers and health authorities should consider educational interventions to increase awareness and knowledge of pharmacists on ASDs. Similarly, pharmacy schools should revise, widen, and deepen educational materials on ASDs in the current curricula.

Community pharmacists are in a key position to provide crucial information to individuals with chronic disease and disabilities, including ASDs. The current study revealed gaps in awareness and knowledge of ASDs among community pharmacists in, Khartoum state, Sudan. Participants in this study reported low confidence in their ability to dispense and counsel individuals with ASDs and their families on medications used to alleviate symptoms of ASDs. Community pharmacists reported low familiarity with resources devoted to ASDs in their community, these gaps could be filled by specifically designed educational interventions.

\section{CONFLICTS OF INTEREST}

Nadine Hassan Ali and Ahmed H. Arbab report no conflicts of interest associated with this article. 


\section{REFERENCES}

1. Mormann, M.; Gilbertson, C.; Milavetz, G.; Vos, S. Dispelling vaccine myths: MMR and considerations for practicing pharmacists. J. Am. Pharm. Assoc. 2012, 52, 282-286.

2. Christensen, D.L.; Braun, K.V.; Bao, J.; Bilder, D.; Charles, J.; Constantino, J.N.; Daniels, J.' Durkin, M.S.; Fitzgerald, R.T.; Kurzius-Spencer, M..; Lee, L.C. Prevalence and characteristics of autism spectrum disorder among children aged 8 years autism and developmental disabilities monitoring network, 11 sites, United States, 2012, MMWR Surveill Summ. 2018, 65,1-23.

3. Autism Speaks. What is autism? Available at:http://www.autismspeaks.org/what-autism. [Accessed on April 5.2019]

4. Leung, A.K.; Kao, C.P. Evaluation and management of the child with speech delay. Am. Fam. Physician. 1999, 59, 3121-3128.

5. Rice, C, Nicholas, J.; Baio, J, Pettygrove, S.; Lee, L.C.; Braun, K.V; Doernberg, N.; Cunniff, C.; Newschaffer, C.; Meaney, F.J; Charles, J. Changes in autism spectrum disorder prevalence in 4 areas of the United States. Disabil. Health J. 2010, 3, 186-201.

6. Hertz-Picciotto, I.; Croen, L.A.; Hansen, R.; Jones, C.R.; Van de Water, J.; Pessah, I.N. The charge study: an epidemiologic investigation of genetic and environmental factors contributing to autism. Environ. Health Perspect. 2006; 114, 1119-1125.

7. Tsai, L. Y. Psychopharmacology in autism. Psychosom. Med. 1999, 61, 651-665.

8. Kaplan, G.; and McCracken, J.T. Psychopharmacology of autism spectrum disorders. Pediatr. Clin. North Am.2012, 59, 175-187

9. Mohiuddin, S.; Ghaziuddin, M. Psychopharmacologyof autism spectrum disorders: A selective review. Autism .2013 $17,645-654$.

10. Steckler, T.; Spooren, W.; Murphy, D. Autism spectrum disorders-an emerging area in psychopharmacology. Psychopharmacology, 2014, 231, 977-978.

11. Esbensen, A. J.; Greenberg, J. S.; Seltzer, M. M.; Aman, M. G. A. longitudinal investigation of psychotropic and non-psychotropic medication use among adolescents and adults with autism spectrum disorders. J. Autism Dev. Disord., 2009, 39, 1339-1349.

12. Mandell, D. S.; Morales, K. H.; Marcus, S. C.; Stahmer, A. C.; Doshi, J.; Polsky, D. E. Psychotropic medication use among Medicaid-enrolled children with autism spectrum disorders. Pediatrics. 2008; 121: e441-e448.

13. McAuley, J. W.; Miller, M. A.; Klatte, E.; Shneker, B. F. Patients with epilepsy's perception on community pharmacist's current and potential role in their care. Epilepsy Behav. 2oog, $14,141-145$.

14. Handen, B. L.; Johnson, C. R.; Lubetsky, M. Efficacy of methylphenidate among children with autism and symptoms of attention-deficit hyperactivity disorder. J. Autism Dev. Disord. 2000; 30, 245-255.

15. Marrosu, F.; Marrosu, G.; Rachel, M. G.; Biggio, G. Paradoxicalreactions elicited by diazepam in children with classic autism. Funct. Neurol. 1987, 2, 355-361.

16. Khanna, R.; Jariwala, K. Awareness and knowledge of autism among pharmacists. Res Social Adm Pharm, 2012, 8, 464-471.

17. Luleci, N. E.; Hidiroglu, S.; Karavus, M., Karavus, A; Sanver, F.F.; Ozgur, F.; Celik ,M.; Celik S.C. The pharmacists' awareness, knowledge and attitude about childhood autism in Istanbul. Int. J. Clin. Pharm. 2016, 38, 1477-1482. 
18. Shawahna, R.; Fahed, B., Qadri, D.; Sharawi, L.; Soroghli, M.; Dweik, M. Awareness and Knowledge of Autism Spectrum Disorders Among Pharmacists: A Cross-Sectional Study in Palestinian Pharmacy Practice J. Autism Dev. Disord. 2017, 47, 1618-1627.

19. Federal Ministry of Health, Sudan, Annual Pharmaceutical Statistical Report, 2006. Available,from:http://apps.who.int/medicinedocs/documents/s17176ar/s17176ar.pdf, FMOH Khartoum. [accessed on April7, 2018]

20. Khanna, R.; Jariwala, K.; Holmes, E. R.; Ramachandran, S. Autism familiarity and knowledge among pharmacy students. Curr Pharm. Teac.h Learn. 2014, 6, 150-157.

21. Schwartz, H.; Drager, K. D. Training and knowledge in autism among speech-language pathologists: A survey. Lang. Speech Hear. Ser. 2008, 39, 66-77.

22. Strunk, J. A. School nurses' knowledge of autism spectrum disorders. J. Sch. Nurs., 2009;25, 445-452.

23. Freeman, B. J. Guidelines for evaluating intervention program for children with autism. J. Autism Dev. Disord. 1997, 27, 641-651.

24. Wiggins, L. D.; Baio, J.; Rice, C. Examination of the time between first evaluation and first autism spectrum diagnosis in a population-based sample. $J$ Dev Behav Pediatr. 2oo6, 27, S79-S87.

25. McAuley, J.; Mott, D.; Schommer, J.; Moore, J.; AL, R. Assessing the needs of community pharmacists and primary care physicians in providing care to patients with epilepsy. J. Am. Pharm. Assoc.1999, 39: 499-504.

26. Hattier, M. A.; Matson, J. L.; Tureck, K., Horovitz, M. The effects of gender and age on repetitive and/or restricted behaviors and interests in adults with autism spectrum disorders and intellectual disability. Res Dev Disabil. 2011, 32: 2346-2351.

27. Grabenstein, J. D.; Hartzema, A. G.; Guess, H. A.; Johnston, W.P. Community pharmacists as immunization advocates: A pharmacoepidemiologic experiment. Int.J. Pharm. Pract. 1993, 2:5-10.

28. Novella, S. The anti-vaccination movement. SkepticalInquirer.2016, 31, $26-31$.

29. Smith, M. J.; Ellenberg, S. S.; Bell, L. M.; Rubin, D. M. Media coverage of the measlesmumps-rubella vaccine and autism controversy and its relationship to MMR immunization rates in the United States. Pediatrics. 2008, 121, e836-e843.

30. Gillespie-Lynch, K.; Brooks, P.J.; Someki, F.; Obeid, R.; Shane-Simpson, C, Kapp S.K; Daou, N, Smith D. S. Changing college students' conceptions of autism: An online training to increase knowledge and decrease stigma. J. Autism Dev. Disord.2015, 45: 2553-2566. 